\title{
Development prospects of mobile rice straw crushers
}

\author{
Ivan Masienko ${ }^{1, *}$, Darya Fedulenko ${ }^{1}$, and Valentin Tatarintsev ${ }^{1}$ \\ ${ }^{1}$ FSBEI HE «Kuban State Agrarian University named after I.T.Trubilin», 350044 Krasnodar, Russia
}

\begin{abstract}
The article presents an analysis of prospects of development of mobile crushers for utilization of rice straw using the method of assessing engineering and technical significance of inventions. The method consists of study of retrospective patent fund for previous 10-15 years which allows to make forecast of possible ways of technology development for the next 10-15 years. Based on obtained data of a patent, there was designed the graph of change in level of prospects of combine harvesters and mobile crushers by years of research. The presented results of forecast data showed that development of mobile crushers is a promising trend.
\end{abstract}

Krasnodar Territory is a main agricultural region of Russia, where more than $80 \%$ of rice is produced.

Every year, rice is grown on area of 130 - 135 thousand hectares in Krasnodar Territory, and its gross production reaches 900 thousand tons. In the coming years, it is planned to increase production of rice to 1.0 million tons.

But with increase in rice production, production of rice straw is increased too, which hitherto finds applications neither in agriculture nor in industry because of its specific features $[1,2]$.

The utilization of rice straw by embedding it in the soil is the only possible and appropriate in this situation. Qualitatively crushed and split non-grain part of the rice crop is an excellent organic fertilizer [3].

It was found that rice straw, which was embedded in surface soil layer since autumn, activates functioning of organisms, promotes mobilization of elements of mineral nutrition and increases yield of rice, and also significantly affects the replenishment of carbon reserves in soil [1]. The greatest mobilization of carbon of rice straw in humus occurs while introducing different types of nitrogen fertilizers.

In soil fertilized with rice straw, there is an extremely active reproduction of saprophytic microorganisms, which affects mobilization of nutrients for plants. Yield increase under rice straw introduction occurs mainly due to better assimilation of soil nitrogen reserve.

The main obstacle to use rice straw as organic fertilizer is crushing and embedding of straw into soil, because it differs greatly from straw of grain crops. At present, both crushing and embedding of rice straw into soil are not technically worked out, that does not allow the use of technology of utilization of IPA (initial part of accelerator) with embedding of straw into soil in production scales [4].

\footnotetext{
${ }^{*}$ Corresponding author: ivan.masienko@yandex.ru
} 
The process of rice straw crushing can be performed in two ways: by crusher installed on harvester simultaneously with rice threshing, and mobile crusher operating separately from harvester with picking-up of straw from roller [5, 6].

Preliminary results of our research of technology of rice straw crushing with subsequent embedding into soil showed that quality of mobile trailed crushers in some cases is much higher than quality of crushers hung on rice harvesters [6].

Moreover, when using a hinged shredder, combine harvester's performance is reduced by $30 \%$, fuel consumption is increased by $15 \%$, and its service life is reduced by quarter. Power consumption of rice harvester engine for shredder's drive reaches $45-50 \mathrm{~kW}$. Therefore, providing rice harvester with function of rice straw crushing, accompanied by a significant decrease in its productivity, leads to increase in time and reduces quality of harvesting $[7,8]$.

However, should we assume that mobile shredders are the most promising among rice straw crushers?

The answer to this question can be obtained as a result of scientifically based forecast based on patent developments for the period of researches.

Forecasting is now an integral part of scientific research, allowing to establish its most promising areas, contributing to selection of the most likely and optimal solutions to various research issues.

The analysis of prospects for development of shredders for straw utilization was performed by us for the period from 2001 to 2015 using the method of assessing engineering significance of inventions.

The initial problem underlying forecasting methodology is a statement that study of retrospective patent fund for the previous 10-15 years allows to make forecast of possible ways of technology development for the next 10-15 years [9].

Selection of inventions was carried out according to developed structural scheme of classification of straw shredders [10].

Transfer of patent information into quantitative characteristics was performed by determining completeness coefficient of invention according to the formula:

$$
G=\frac{\sum_{i=1}^{n} P_{i j} \varphi(i)}{P_{\max } \sum_{i=1}^{n} \varphi(i)}
$$

where $P_{i j}$ - evaluation in scores, $j$ - position, $i$ - characteristic;

$\varphi(i)$ - function that normalizes the weight of characteristics in a ranked sequence;

$n$ - number of characteristics;

$P_{\max }-$ maximum evaluation in scores.

Otherwise, coefficient of completeness of invention was ratio of sum of estimates of the patent or invention $q$ to maximum possible sum $Q$.

$$
G=\frac{q}{Q}
$$

For each invention the estimate $P_{i j}$ was determined in accordance with general definition table (GDT). On the basis of this table and formula, an algorithm of transposing qualitative features of patent solution into completeness coefficient was developed and a characteristic matrix was compiled.

It follows from evaluation matrix that maximum possible assessment of invention or patent $P_{\text {max }}$ in scores is 22,030; minimum $P_{\min }$ is 4,446 .

To determine prospects of selected competing groups of patent solutions after evaluation of a single invention, we found the number of inventions - $M_{i}$, nominal flow of inventions $-N_{\mathrm{n}}$ and generalized completeness coefficient $-G_{o}$. 
The generalized completeness coefficient is defined as ratio of certain integrals for present and nominal flows of patent information:

$$
G_{o}=\frac{\int_{t_{H}}^{t_{n}} M_{i}(t) d t}{\int_{t_{H}}^{t_{k}} N_{n}(t) d t}
$$

where $t_{k}, t_{n}$ - time, for which inventions are estimated, $t_{n}=2001, t_{k}=2015$.

Function $\mathrm{M}_{i}(\mathrm{t})$ is drawn in points which is defined by value:

$$
M_{i}(t)=\sum_{i=1}^{n} G_{i}
$$

where $G_{i}$ - coefficient of completeness $i$ of invention from amount $n$ of authors' certificates obtained to the moment of time $t$.

In accordance with adopted system of estimates, quantitative characteristics were introduced to determine prospects of inventions by completeness coefficients $G, G_{o}$.

Boundaries of levels of prospects determined on the basis of evaluation matrix with regard to $P_{\max }, P_{\min }$ which are presented in Table 1 .

Table 1. Table of prospects of competing groups of inventions.

\begin{tabular}{|c|c|}
\hline Value of completeness coefficient & Level of prospects \\
\hline $0,80 \ldots 1,00$ & High \\
\hline $0,60 \ldots 0,799$ & Above the middle \\
\hline $0,40 \ldots 0,599$ & Middle \\
\hline $0,20 \ldots 0,399$ & Low \\
\hline
\end{tabular}

Values $M_{i}, G_{o}$ found according to formulas (3 and 4) for selected competing groups of inventions are presented in Table 2.

Table 2. Value of chanced and nominal numbers of inventions and chanced coefficient of completeness for straw crushers

\begin{tabular}{|c|c|c|c|}
\hline $\begin{array}{c}\text { Competing groups of } \\
\text { inventions }\end{array}$ & $\begin{array}{c}\text { Chanced number of } \\
\text { inventions }\end{array}$ & $\begin{array}{c}\text { Nominal number of } \\
\text { inventions }\end{array}$ & $\begin{array}{c}\text { Generalized coeffi- } \\
\text { cient of complete- } \\
\text { ness }\end{array}$ \\
\hline $\begin{array}{c}\text { Mobile trailed crush- } \\
\text { ers }\end{array}$ & 12,41 & 13 & 0,954 \\
\hline $\begin{array}{c}\text { Hinged combine } \\
\text { crushers }\end{array}$ & 10,68 & 12 & 0,89 \\
\hline
\end{tabular}

The number of progressive patents in particular direction of development of agricultural machinery can be represented in form of a normal distribution curve.

Regression lines were constructed on the assumption that a patenting curve is an exponent described by the equation:

$$
N=N_{0} e^{b t}
$$

where $N$ - amount of progressive patents according present research:

$N$ - number of patents in the beginning of period;

$t$ - time of forecast;

$b-$ exponential coefficient. 
Exponential coefficient took for criteria of present research prospects. If $b$ had mark «plus», the trend was in stage of growth, if it was «minus», it regressed.

If we find a logarithm of the equation (5), we obtain

$$
\ln N=\ln N_{O}+b t
$$

The equation (5) was used to draw linear regression and to find prospects due to its criteria.

On the basis of obtained data of patents, we build a graph (Figure 1) of development of straw shredders (according to criterion of prospects)

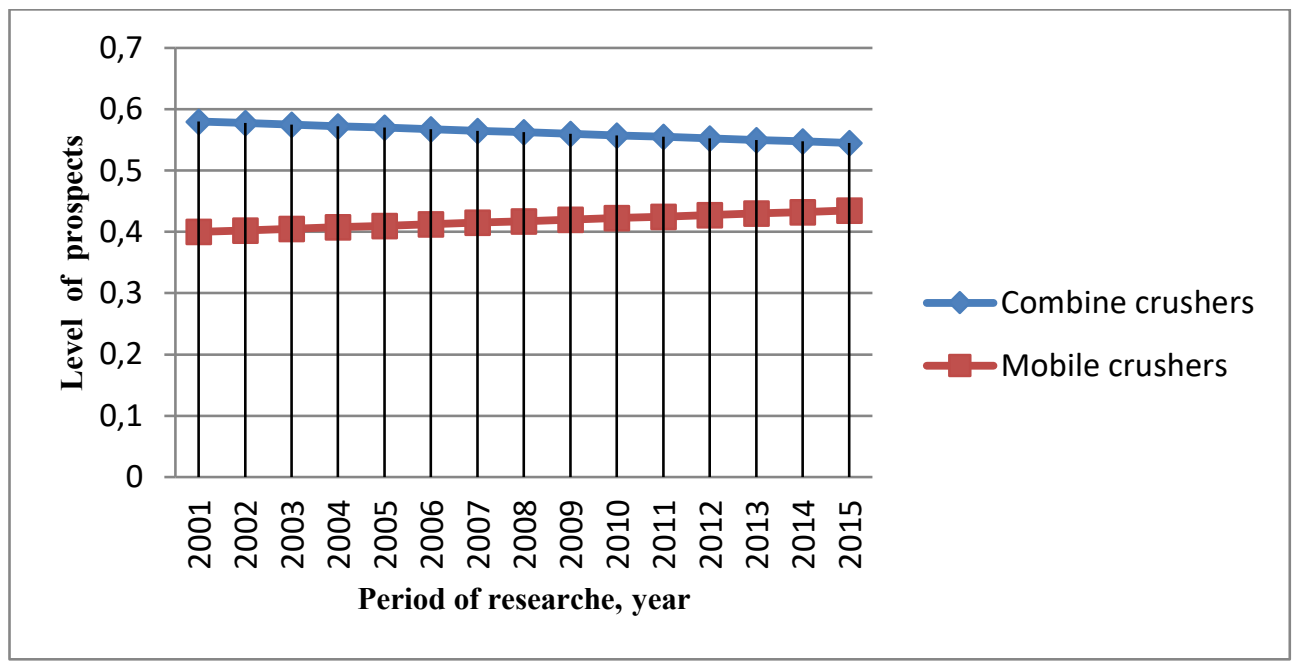

Fig. 1. Graph of changes in level of prospects of trailed combine harvesters and mobile shredders by years of researches

Analyzing graph data, we can make following forecast conclusions that mobile shredders have a high level of prospects $G o=0,743$ with positive value of exponential coefficient $b=+0,0380$, it justifies about progressing this trend and increase of invention activity in designing mobile crushers. As for crushers, value of exponential coefficient has a value of $b=-0,0320$, which indicates a decrease in inventive activity. Thus, forecast data show that creation of mobile crushers is a promising direction.

\section{References}

1. M. Chebotaryev, I. Masienko, V. Masienko, G. Grigoryan, Rice straw utilization by crushing and splitting with bayonet-cutting roller, Polythematic network electronic scientific journal of Kuban State Agrarian University, 133, p. 486-497 (2017)

2. M. Chebotaryev, I. Masienko, Technological aspects of rice straw utilization in rice growing of Krasnodar Territory, Rice growing, 2 (25), p. 31-35 (2014)

3. M. Chebotaryev, I. Masienko, G. Grigoryan, V. Gritsunov, Trailed rice straw crusher PIRS-2-2, Agricultural expert in mechanization, 10, p. 38-39 (2018)

4. M. Chebotaryev, Digital technologies in rice growing, 73, p. 335-336 (2018)

5. I. Tron, M. Chebotaryev, Methods of utilization of non-grain part of rice in conditions of Krasnodar Territory, 73, p. 415-419 (2018) 
6. G. Zelensky, M. Chebotaryev, T. Logoida, Improvement of technology of rice cultivation in sanitary zones (On example of experimental training farm "Kuban»), Proceedings of Kuban State Agrarian University, 74, p. 53-57 (2018)

7. M. Chebotaryev, E. Shapiro, A.Taran, Determination of total number of rice harvesters with given warranty probability, Agricultural expert in mechanization, 7-8, p. 71-86 (2018)

8. M. Chebotaryev, E. Shapiro, A. Taran, Calculation of rice harvesters' number of main technological level of harvesting-transport complex, Rice growing, 4(41), p. 56-59 (2018)

9. M. Chebotaryev, Prospects of development of machines for processing rice field soil, 72, p. 339-340 (2017)

10. M. Chebotaryev, Modern condition and prospects of development of machines for rice growing, p. 239-245 (2016) 